Bioscientia Medicina Volume 3, Issue 3 , Page No: 34-40

Available online : www.bioscmed.com Bio Sc Med 3(3) :34-40

\title{
Screening A Trinucleotide Repeat Expansion: How precise PCR can be?
}

\author{
Ziske Maritska $^{1 *}$, Baharudin Baharudin ${ }^{2}$, Ardy Santosa ${ }^{3}$, Ching Leng Kee ${ }^{4}$, Tan Yue \\ Ming $^{4}$, Sultana MH Faradz ${ }^{2}$
}

\author{
${ }^{1}$ Department of Biology Medicine, Faculty of Medicine, Universitas Sriwijaya, Palembang, Indonesia \\ ${ }^{2}$ Division of Human Genetics, Center for Biomedical Research Faculty of Medicine Diponegoro University, \\ Semarang, Indonesia \\ ${ }^{3}$ Department of Urology, Dr. Kariadi Hospital, Semarang, Indonesia \\ ${ }^{4}$ DNA Diagnostic and Research Laboratory, Kandang Kerbau Hospital, Singapore
}

\# Correspondence: ziske_kamil@yahoo.com

Received : June 29th 2019

Accepted :August $25^{\text {th }} 2019$

\section{Background}

\section{ABSTRACT}

Trinucleotide Repeat Expansion (TRE) in human DNA could lead to various diseases. An expanded CAG repeat (>31 or 37 repeats, depends on the ethnicity) in Androgen Receptor gene is suggested to be associated with the occurrence of isolated hypospadias. In an effort to identify the exact numbers of repeats, sequencing has been the most favored method to be conducted despite its cost.

\section{Objective}

This study wished to investigate the possibilities of using Polymerase Chain Reaction (PCR) method to screen expanded repeats in isolated hypospadias, as one of the TRE diseases.

Methods

Numbers of CAG repeat in twelve hypospadias patients and one normal male was first predicted from the visualization of PCR products in $3 \%$ agarose gel electrophoreses with $20 \mathrm{bp}$ ladder marker before it was finally sequenced.

Results

Two samples gave the same exact result, while the rest showed a range of 1-11 bp differences. Statistically, there was a significant difference between the mean of CAG repeats from PCR method $(M=26.1667, S D=6.71272)$ and the mean of $C A G$ repeats from sequencing $(M=23.75, S D=5.70685) ; t(11)=$ $4.570, \mathrm{p}=0.001$. Furthermore, the sensitivity of PCR was $100 \%$ and the specificity was $83.33 \%$.

Conclusion

It can be concluded that PCR method could be used as a screening method in identifying TRE with large numbers of repeats. However, PCR in TRE disease with small numbers of expanded repeats needs to be followed by sequencing in order to obtain the exact numbers of repeats.

Keywords: Trinucleotide Repeat Expansion, Polymerase Chain Reaction, Sequencing, Isolated Hypospadias

\section{Introduction}

It has been long identified that some genetic diseases are caused and/or associated with a trinucleotide repeat expansion in its patients' gene sequence. The trinucleotide repeats found in humans are varied from a CGG repeat in Fragile X Syndrome, to CAG repeat in numerous 
genes related to various conditions. ${ }^{1}$ One of the CAG repeats under discussed is the relation between an expanded CAG repeats in Androgen Receptor $(A R)$ gene and hypospadias. ${ }^{2,3,4}$

Hypospadias itself is one of the most common urogenital birth defect found in newborn males where the urinary meatus is abnormally located. ${ }^{5,6}$ Previous studies suggested that the length of CAG repeat in $A R$ gene may affect its transcriptional activity, hence leading to insufficient androgenic action which causes undervirilization in male fetus. ${ }^{2,3,4}$

The CAG repeat consensus sequence in $A R$ gene is (CAG)nCAA..$^{3,4,7}$ The length of CAG trinucleotide repeat in the normal population spans around 8-37 repeats with a mean length of 20-23 repeats, yet it may varies, depending on the race. ${ }^{3,4,7}$ The repeat sequence begins from bp 596 to approximately bp 630, depends on the polymorphism. ${ }^{2}$ The Asians have 11-31 repeats, with the mean repeat of 23. ${ }^{2,8,9}$ One study conducted by Muniroh et al. showed that Indonesian normal male have the range of CAG repeats of 15-30, with 23 repeats as the median CAG repeat found. ${ }^{10}$

In an effort to identify the cause of this condition, molecular examinations are needed. The widely accepted statement is that sequencing is the most reliable technique in identifying a gene sequence, especially in conditions where numbers of repeats are not quite large. Hence, it is the gold standard test in trinucleotide disease, like in CAG repeats in isolated hypospadias. However, being regarded as a gold standard, sequencing is an expensive method, let alone in Indonesia, where genetic service, even the basic ones has not yet well acknowledged and established in most cities. A way of screening expanded repeats using one of the basic molecular examination like Polymerase Chain Reaction (PCR) is hoped to help diagnose the condition, particularly in countries like Indonesia. This study wished to explore such possibilities.

\section{Methods}

This research took place both in Indonesia and Singapore. DNA samples were provided by the Disorders of Sexual Development (DSD) team of Center for Biomedical Research (CEBIOR), Faculty of Medicine Diponegoro University Semarang. DNA analysis of the variation of CAG repeat in $A R$ gene using PCR and sequencing was conducted in the DNA Diagnostic \& Research Laboratory KKH, Singapore.

Twelve samples were selected from male patients who have been clinically diagnosed of having isolated hypospadias by the Disorders of Sexual Development (DSD) team who 
visited Center of Biomedical Research (CEBIOR), Semarang, Indonesia along with one normal healty male who do not have hypospadias from the normal male DNA database in CEBIOR. Informed consent from patients who met the criteria was provided by the DSD team

DNA that has been collected and provided from CEBIOR is extracted by using salting out method. It was then brought to the DNA Diagnostic \& Research Laboratory KKH, Singapore for further steps. The first step in this study was amplifying the CAG repeat of $A R$ gene. Amplification for 13 samples (12 patients' samples and one normal male samples) was performed in a $25 \mu \mathrm{L}$ reaction volume containing $2 \mu \mathrm{L}$ of DNA, $2.5 \mu \mathrm{L}$ of PCR buffer, $1.5 \mathrm{ul}$ of $25 \mathrm{mM} \mathrm{MgCL} 2,2.0 \mathrm{ul}$ of $2.5 \mathrm{mM}$ deoxynucleotide triphosphate, $0.5 \mathrm{ul}$ of $20 \mathrm{mM}$ from each primer, and 0.1 units of Taq polymerase Fermentas and 15.9 sterile water. The CAG repeat were amplified using primers $\operatorname{AIF}$ (5' -AGCCTGTTGAACTCTTCTGAGC -3') as a forward primer and A2R (5' - TCCAGGCTCTGGACGCAACC -3') as the reverse primer. $^{11}$

The PCR reaction was done in the PCR machine AB Biosystem, Verriti 96 well. PCR profile were done in following steps; the DNA was first initially denatured for 3 minutes at $95 \mathrm{C}$; followed by 35 cycles of annealing and extension each in the form of $95^{\circ} \mathrm{C}$ for 30 seconds, $62^{\circ} \mathrm{C}$ for 45 seconds, and $72^{\circ} \mathrm{C}$ for 2 mins 30 seconds; followed with final extension cycle at $72^{0} \mathrm{C}$ for 10 mins and completed with cooling down phase at $15^{\circ} \mathrm{C}$ for some period of time.

Amplicons were then went through the 3\% agarose gel electrophorese running, where numbers of CAG repeats can be estimated roughly by doing manual sizing. The $20 \mathrm{bp}$ ladder marker was used in this 3\% agarose gel electrophorese running. The marker was loaded on each side of the wells that contained samples. Hence, the PCR product size can be estimated more precisely by making straight lines using ruler that connected the lines that marked the PCR product size in the samples' wells and the lines that marked the level of ladder marker next to it.

The PCR product size was being subtracted by the average CAG repeat numbers in world population. Take for example, the expected PCR product size with $22 \mathrm{CAG}$ repeats is $486 \mathrm{bp}$. If in the visualization of PCR product we found a $500 \mathrm{bp}$ PCR product size, it means that the estimated CAG repeat numbers were around 26-27 repeats. The sequencing analysis was also done at the DNA Diagnostic \& Research Laboratory KKH, Singapore to obtain the exact 
number of CAG repeats of those samples so that it can be compared to those results from PCR method.

\section{Results}

There were thirteen samples being involved in this study. The result of both PCR and sequencing method for the selected thirteen samples can be seen on table 1 below.

Table 1. Estimated CAG repeat numbers based on PCR and numbers of CAG repeat confirmed by sequencing on 13 selected samples with no CAG repeats after interruption count

\begin{tabular}{lll}
\hline Sample & $\begin{array}{l}\text { Estimated based on manual } \\
\text { size screening }\end{array}$ & $\begin{array}{l}\text { Confirmed based on } \\
\text { sequencing }\end{array}$ \\
\hline Sample 2 & 30 & 27 \\
Sample 6 & $36-37$ & 34 \\
Sample 7 & $26-27$ & 27 \\
Sample 8 & 17 & 16 \\
Sample 14 & 17 & 17 \\
Sample 16 & 30 & 28 \\
Sample 22 & 33 & 28 \\
Sample 23 & 30 & 25 \\
Sample 26 & 23 & 22 \\
Sample 27 & 30 & 25 \\
Sample 32 & 17 & 15 \\
Sample 33 & 23 & 21 \\
Normal Male & 33 & 22 \\
\hline
\end{tabular}

From the thirteen samples that had undergone both methods, a measure of sensitivity and specificity for PCR was conducted. The positive group is all the samples who had expanded CAG repeat, while the negative group is all the samples whose CAG repeat is within normal range. From the calculation, the sensivity of PCR was $100 \%$ and the specificty was $83.33 \%$. In addition, PCR positive predictive values (PPV) was 33.33\%, negative predictive values (NPV) was $100 \%$, the positive likelihood ratios (PLR) and negative likelihood ratios (NLR) were 6.00 and 0.00 respectively with a $7.69 \%$ prevalence, as it can be seen in table 2 below.

Table 2. Sensitivity and Specificity of PCR vs. Sequencing

\begin{tabular}{lllll}
\hline & & \multicolumn{2}{l}{ Sequencing } & Total \\
\cline { 3 - 5 } & & $(+)$ & $(-)$ & 3 \\
PCR & $(+)$ & 1 & 2 & 10 \\
& Total & 0 & 10 & 13 \\
\hline Se $=100 \%$ & 1 & 12 & NPV=100\% \\
PLR $=6.00$ & Sp=83.33\% PPV $=33.33 \%$ & & & \\
Prevalence $=7.69 \%$ & NLR $=0.00$ & &
\end{tabular}


Se: sensitivity, Sp: specificity, PPV: positive predictive value, NPV: negative predictive value, PLR: positive likelihood ratio, NLR: negative likelihood ratio

\section{Discussion}

From the results above, it can be seen that there are some differences found between the result of estimated CAG repeats obtained from manual size screening and ones that are confirmed through sequencing. Few samples showed quite a discrepancy, few showed a slight difference, yet there were also samples who showed a same result from both two methods. A paired sample t-test was conducted to compare the numbers of CAG repeats from PCR method and from sequencing result in the selected thirteen samples. There was a significant difference between the mean of CAG repeats from PCR method $(M=26.1667$, $\mathrm{SD}=6.71272)$ and the mean of $\mathrm{CAG}$ repeats from sequencing $(\mathrm{M}=23.75, \mathrm{SD}=5.70685)$; $\mathrm{t}(11)=4.570, \mathrm{p}=0.001$.

However, this study only roughly predicted the CAG repeat length by manual sizing from the PCR product size. This technique is not as accurate as the sequencing or other method, yet at least it shows the general view on CAG repeat length average found in both patients and normal male. The CAG repeat numbers of all the samples from the two different methods, which are PCR and sequencing showed some variations in results. There is a significant difference found when means from both methods were compared by using the paired sample t-test. However, although both methods showed a statistically significant difference, in raw data, the CAG repeat numbers obtained from these two methods were not really discrepant. Those two methods are three points apart in terms of means, and one point apart in terms of standard deviation, leading to a conclusion that these two methods have more or less four repeats differences when yielding a result.

A screening of expanded CAG repeats in isolated hypospadias patients with lower cost yet high sensitivity and specificity is needed in a way to reduce unnecessary sequencing. From the calculation, the sensitivity of PCR in picking up expanded CAG repeats in patients is $100 \%$, while the specificity of PCR is as big as $83.33 \%$. Nevertheless, one thing to be noted is the number of samples who undergone both PCR and sequencing in this study is not many. Moreover, the sensitivity and specificity being measured here is the ability of PCR to pick up a person with an expanded CAG repeat length beyond its normal range, not the sensitivity and specifity of PCR in determining the size of the CAG repeats in a person. 
However, considering on how expensive the cost of sequencing is, -based from this result-, the use of PCR method where the visualization of PCR product size is conducted in $3 \%$ agarose gel electrophorese using $20 \mathrm{bp}$ marker ladder could provide a screening measurement prior to sequencing by giving early estimation on whether CAG repeats in a patient is expanded or not.

\section{CONCLUSION}

The result of this study implies that PCR method solely does not suffice as the only method used in identifying the exact numbers of CAG repeats of $A R$ gene in isolated hypospadias cases. To date, the most commonly used technique or method in investigating expanded repeats is PCR followed by sequencing to yield the accurate numbers of repeats in a patient.

\section{ACKNOWLEDGEMENTS}

This research is made possible by scholarship from Biro Perencanaan Kerjasama Luar Negeri (BPKLN), Ministry of Education, Indonesia for the opportunity to enrol in Masters in Biomedical Science majoring in Genetic Counseling and a fellow in Kandang Kerbau Hospital Singapore.

\section{REFERENCES}

1. Claude TA, Warren ST. Trinucleotide repeat expansion and human disease. Annu Rev genetics. 1995;29:703-728.

2. Nenonnen H. Functional characterisation of the CAG polymorphism in the androgen receptor (In vito and In Vivo) [Doctoral dissertation]. Lund University;2011 [Cited 2012 Dec 28].

3. Hsing AW, Gao YT, Wu G, et al. Polymorphic CAG and GGN repeat lengths in the androgen receptor gene and prostate cancer risk: a population-based case-control study in China. Cancer Res. 2000;60:5111-5116.

4. Heinlen C, Chang C. Androgen receptor (AR) coregulators: an overview. Endocrine review. 2002;23(2):175-200.

5. Brouwers M, Van Der Zanden LFM, De Gier RPE, Barten EJ, Zielhuis G, Feitz WFJ et al. Hypospadias: risk factor patterns and different phenotypes. BJUI. 2009;105:255-262

6. Leung AKC, Robson WLM. Hypospadias :an update. Asian Journal of Andrology. 2007 Jan;9:16-22.

7. Parada-Bustamante A, Lardone MC, Madariaga M, Johnson MC, Codner E, Cassoria F et al. Androgen receptor CAG and GGN polymorphisms in boys with isolated hypospadias. J Pediatr Endocr Met. 2012;25(1-2):157-162. 
8. Rajender S, Singh L, Thangaraj K. Phenotypic heterogeneity of mutations in androgen receptor gene. Asian Journal of Andrology. 2007;9(2):147-179.

9. Yong EL, Loy CJ, Sim KS. Androgen receptor gene and male infertility. Human Reproduction Update. 2003;9(1):1-7.

10. Muniroh M, Ariani MD, Winarni TI, Juniarto AZ, Faradz SMH. Measurement of CAG Repeat Length Androgen Receptor Gene in 46, XY Indonesian Normal Male Population. Proceedings of The 5th Annual Scientific Meeting of The Indonesian Andrologist; 2011 April 28-30; Jakarta, Indonesia.

11. Cumming CJ, Zoghbi HY. Fourteen and counting: unraveling trinucleotide repeat diseases. Human Molecular Genetics. 2000;9(6):909-916. 